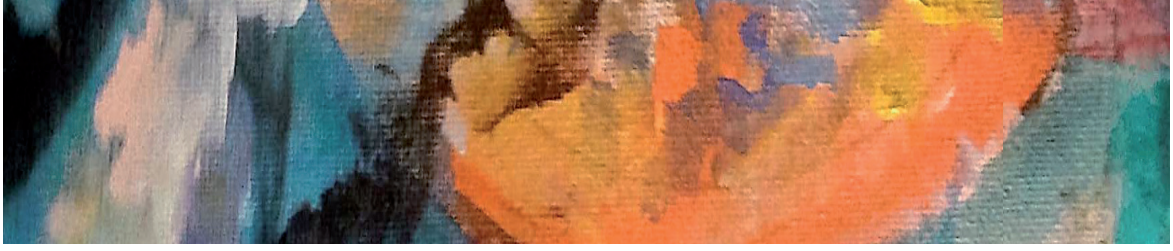

Entreculturas 11 (2021) pp. 20-35 - ISSN: 1989-5097

\title{
RETAZOS DISCURSIVOS DE LA HISTORIA DE LA TRADUCCIÓN: DESDE CICERÓN HASTA LA ILUSTRACIÓN
}

\author{
Discursive Snippets from the History of Translation: \\ from Cicero to Enlightenment \\ (D) Lía de Luxán Hernández \\ Universidad de Las Palmas de Gran Canaria
}

Recibido: 9 de junio de 2020

Aceptado: 12 de diciembre de 2020

Publicado: 27 de febrero de 2021

\begin{abstract}
In this paper, some thoughts on the most remarkable statements of Cicero and Horace on translation are discussed, together with a summary of Dryden's work and an overview on the rules of decorum coming from France. Once the contributions from these authors are considered, achieving a better understanding of translation theory and praxis in the 18th century is easier. This is the point of departure of the next step of this essay, which deals with the phenomenon of translation in the Enlightenment, both in the United Kingdom and in Spain.
\end{abstract}

KEYWORDS: history of translation, Cicero, Horace, Dryden, Spanish and English 18th Century Translation.
RESUMEN

En este artículo se ofrece una breve exégesis de la historia de la traducción desde Cicerón hasta la época ilustrada. Este viaje reflexivo tiene como primera parada unas máximas de Cicerón; luego se desembarca en Horacio y en Dryden; a continuación, se suben a bordo las reglas de decoro provenientes de Francia; y, ya una vez hecho esta primera parte del trayecto, podemos llegar con menos obstáculos a nuestra parada final: la teoría y práctica de la traducción en el siglo XVIII. Nos centraremos solamente en dos puertos: el de Reino Unido y el de España (pero siempre de manera concisa y reflexiva).

PALABRAS CLAVE: historia de la traducción, Cicerón, Horacio, Dryden, traducción del siglo XVIII en España, traducción del siglo XVIII en Reino Unido. 


\title{
RETAZOS DISCURSIVOS DE LA HISTORIA DE LA TRADUCCIÓN
}

\author{
Entreculturas 11 (2021) pp. 20-35
}

\section{INTRODUCCIÓN}

La Antigüedad había sido la infancia de la Traducción: las primeras traducciones del griego al latín (Cicerón, Livio, Terencio, etc.) fueron los primeros pasos [...]. El Medievo había sido la adolescencia, plena de proyectos vitales que dieron la base para el ulterior desarrollo cultural del mundo eurocéntrico: Bagdad y Toledo fueron intentos de sentar una personalidad comunicativa entre las diversas épocas y naciones de la sociedad humana. [...] En el Renacimiento asistimos a la edad viril [...] de la traducción. [...] A partir del humanismo, la traducción empieza a contar en la vida pública de las naciones [...] La pérdida de contacto con las lenguas de la Antigüedad obliga al hombre cultivado a leer los clásicos en su lengua vernácula. A ello ayuda el arte de la impresión del libro [...] [que] será factor determinante en la dinamización cultural y social de la traducción [...] (Vega Cernuda 1996: 71).

“Todo proceso cultural, y la traducción lo es, tiende a ser estudiado y descrito desde una perspectiva historicista” (Ruiz Casanova 2000: 36). La traducción ha acompañado al hombre en todas las etapas de la historia, siendo impulsora de muchos de los cambios culturales y sociales. La traducción debe estudiarse en la historia y como parte de ella. Se hace necesario citar aquí las ventajas que señala D 'Hulst en cuanto a la consecución de un análisis histórico de la traducción (1994: 12-13), y que autores como Delisle (2003: 222), Lafarga y Pegenaute (2004: 14) tienen en consideración al resaltar la importancia del estudio de la historia de la traducción:
a) facilitar al neófito una excelente vía de acceso a la disciplina;
b) proporcionar al investigador la flexibilidad inte- lectual necesaria para enfrentarse a nuevas maneras de pensar (se supone la traducción);
c) incitar a una mayor tolerancia ante formas even-

tualmente desviadas de pensar las cuestiones de traducción;

d) constituir prácticamente el único medio de encontrar la unidad de la disciplina, relacionando el pasado con el presente;

e) permitir a los traductores recurrir a modelos del pasado.

\section{LA INFLUENCIA DE CICERÓN}

Los primeros testimonios del método que debe seguirse a la hora de emprender la tarea de la traducción datan del año 46 a.C. y vienen de la mano de Cicerón, en un escrito a modo de introducción a las traducciones de unos discursos de Esquines y Demóstenes, titulado De optimo genere oratorum (aunque cabe mencionar que no se han localizado ninguna de las referidas traducciones). Aquí mostramos un fragmento, traducido por García Yebra, aunque hemos tenido que corregir la acentuación y puntuación en algunas partes del texto - también ha de aclararse que la negrita es nuestra- (García Yebra 1994: 139-140):

Mas, por ser grande el error en lo relativo a esta manera de hablar [en estilo ático], pensé que debía emprender un trabajo útil para los estudiosos, aunque para mí innecesario. Por eso vertí los discursos más famosos, y opuestos entre sí, de los dos oradores áticos más elocuentes, Esquines y Demóstenes, pero no los vertí como intérprete, sino como orador, con las mismas ideas y con sus formas a modo de figuras, pero con palabras acomodadas a nuestro uso. No me pareció necesario volver palabra por palabra, pero conservé todo su estilo y su fuerza. Pues no me consideré obligado a contárselas al lector, sino por decirlo así, a pasárselas.

$\mathrm{Si}$, según creo, he reproducido estos discursos conservando todos sus valores, es decir, los pensamientos y sus figuras y el orden de la exposición, ciñéndome a las palabras sólo en la medida en que no se apartan de nuestro uso -pues aunque éstas no 


\section{Lía de Luxán Hernández}

hayan sido vertidas todas del griego, ciertamente nos hemos esforzado en que sean del mismo estilo-, habrá una norma por la que se rijan los discursos de quienes deseen expresarse al modo ático. Pero no hablemos más de nosotros. Oigamos ya en latín al propio Esquines.

Según Steiner (1981), este precepto de Cicerón es el comienzo del primer período de la traducción, que culminaría con la obra de Tytler titulada Essay on the Principles of Translation (1792) y el ensayo de Schleiermacher Über die verchiedenen Methoden des Übersetzens (1813). El denominador común de esta primera etapa de la traducción se extrae de los comentarios, de las conclusiones y de los análisis de las propias traducciones.

Muchos traductores-teóricos desde la Edad Media hasta el siglo XX van a basarse en las premisas de traducción de Cicerón; y, es más, hoy en día siguen de actualidad. Cicerón nos habla de un enfoque metodológico de la traducción: la transmisión de cultura. Como veremos después, los traductores del siglo XVIII consideraron que uno de los motivos por los cuales se ejercía la labor traductora era, precisamente, por la voluntad de transmitir conocimientos; por lo que concebir que la traducción desempeña una función didáctica es un pensamiento que se repite a lo largo de la historia.

Adviértase también que Cicerón aclara que se ha empleado en esta tarea como un orador y no como un intérprete, hallándose las diferencias en que en el primero de los casos (la opción que escoge como la más idónea) no tiene que contarle las palabras al lector (función entendida entonces como la del intérprete), sino que su misión consiste en pasárselas. Esta opción traductológica se manifiesta en que el agente de la traducción (el traductor-orador en este caso) debe seguir siendo fiel a las ideas y a las formas, pero no a las palabras, que deberá acomodarlas a los usos del latín y solamente deberá apegarse a ellas en el caso de que no contradigan la tradición lingüística de llegada. He aquí de nuevo un claro ejemplo de las disquisiciones teóricas más clásicas en los terrenos filosófico-teóricos de la traducción: ¿traducción literal o libre?
No obstante, García Yebra es de la opinión de que Cicerón no es un verdadero preceptista de la traducción, ni tampoco un traductor en sí, sino un adaptador de textos griegos. Estos son sus argumentos:

1. Cicerón sólo menciona al traductor y, al interpres, para marcar la diferencia entre la manera de verter propia de este y la suya propia, es decir, la que correspondía a un orator.

2. Sólo indirectamente puede deducirse de sus palabras qué entendía por verter como interpres: era sin duda, lo que hoy llamaríamos "traducir literalmente”. Le parecía un procedimiento aceptable para verter ciertas obras, pero inadecuado para exponer las doctrinas de los filósofos griegos y para dar a conocer en Roma las piezas más ilustres de la elocuencia ática.

3. Cicerón nunca pretendió dar normas para la actividad de los traductores, ni sabemos que intentase promover un procedimiento intermedio entre su propia actividad refundidora y la traducción palabra por palabra que practicaban los interpretes, es decir, los traductores de su tiempo (1994:50).

\section{INTERPRETACIÓN DE LAS PALABRAS DE HORACIO}

“Difficile est proprie communicia dicere; tuque rectius iliacum Carmen deducis in actus quam si proferres ignota indictaque primus. publica materies privati iuris erit, si non circa vilem patulumque moraberis orbem, nec verbo verbum curabis reddere fidus interpres

(versos 128-132 de Arte Poética)

Muchos teóricos de la traducción observan en estas palabras un claro ejemplo del fidus interpretes (cf. Fernández 2009) y, como veremos más adelante, del antimodelo de 


\section{RETAZOS DISCURSIVOS DE LA HISTORIA DE LA TRADUCCIÓN}

traducción dieciochesco; pero autores como Steiner (1975) y García Yebra (1994) advierten que Horacio no es un preceptista de la traducción, sino que sus palabras están dirigidas al poeta, quien puede hacer uso de trabajos literarios anteriores, sin acudir a métodos de "palabra por palabra", como un traductor "fiel".

\begin{abstract}
$\mathrm{Al}$ escribir estos versos, Horacio no da consejo a traductores, sino a jóvenes poetas: no deben éstos buscar a toda costa la originalidad en lo que dicen, sino en la manera de decirlo. No es fácil tratar con novedad temas comunes; pero quizá tú, joven poeta, puedes escenificar un canto de la Ilíada con más acierto que si presentaras argumentos desconocidos, nunca tratados antes por nadie. La materia pública pasará a ser tuya si no te quedas en un círculo bajo y trillado, y no tratas de reproducir el argumento palabra por palabra como fiel intérprete (García Yebra 1994: 55).
\end{abstract}

Aunque ya en el siglo XVIII, Sherburne había advertido este error:

\begin{abstract}
And among these not a few who profess themselves Enemies to all Translations that keep close and near to their Originals: grounding their unwarrantable Dislike of that way of Traduction, upon a mistaken and misaply'd Passage in Horace his de Arte Poetica, where they fancy he gives Rules for Translation, and particularly condemns that which they call a Verbal one. I think it not unnecessary to insert something in this place to shew the Erroneousness of that Opinion, and undeceive those who are heedlessly draw away from truly understanding the Mind of Horace [...] (Steiner 1975: 88).
\end{abstract}

García Yebra (1994: 54) nos remonta a San Jerónimo para descubrirnos el error en la interpretación de estas palabras de Horacio, pues fue el primer teórico de la traducción que consideró que estas voces tenían un significado parecido a las de Cicerón que hemos transcrito con anterioridad.

No deja de extrañarnos, es cierto, que entienda la expresión fidus interpres como vocativo; como si Horacio dijese:
"Fiel traductor no procurarás verter palabra por palabra". El vocativo sería fide. Pero Horacio usa aquí el nominativo, que en este pasaje tiene valor casi predicativo: "No procurarás reproducir palabra por palabra [convirtiéndote así en] fiel traductor".

\section{EL CONCEPTO DE IMITACIÓN DE LA TRADUCCIÓN}

Desde Platón, es muy común referirse al arte como un tipo de imitación. A pesar de que los estudios de traducción no hayan sido objeto de parangón en este sentido hasta épocas bastante tardías debido a su no consideración como campo de conocimiento o de estética, la traducción puede ser vista como arte; de ahí que no nos tenga que resultar extraño que se aluda al concepto de "mímesis" a la hora de explicar enfoques traductológicos. Dryden, entre otros, compara la traducción con las piezas de arte y la pintura en general:

When a painter copies from the life, I suppose he has no privilege to alter features and lineaments, under pretence that his picture will look better: perhaps the face which he has drawn would be more exact, if the eyes or nose were altered; but 'tis his business to make it resemble the original (Essays, I: 242; citado en Steiner 1975: 35-36).

Abrams (1953) refleja la evolución que ha experimentado el concepto de mímesis a lo largo de la historia (cf. también Steiner 1975 y Fernández 2009) y advierte dos grandes corrientes: naturalismo e idealismo. Dentro del idealismo, nos encontramos con dos enfoques: el planteado por Platón (idealismo trascendental) y el auspiciado por Aristóteles (idealismo empírico). Aplicando el concepto de mímesis al campo de la traducción, habría que decir que el estandarte de la vertiente naturalista sería "la traducción ad pedem litterae"; mientras que la filosofía traductora del enfoque idealista sería algo así como "la traducción del subsuelo del TO (texto origen)”. En el supuesto de los partidarios de Platón, la traducción sería la tercera representación de la realidad, una sombra de una apariencia; mientras que 


\section{Lía de Luxán Hernández}

Entreculturas 11 (2021) pp. 20-35

los partidarios del idealismo empírico concebirían la traducción como una imitación de lo visible en el texto origen, aunque con otras palabras, modos, formas y expresiones.

\section{LO FRANCÉS Y LAS BELLES INFIDÉLLES}

Las traducciones del siglo XVIII son bellas, pero infieles: guardan el decoro y la estética francesa, pero no son leales ni con el texto meta, ni con el autor: son, en muchos de los casos, adaptaciones en el sentido estricto de la palabra. Lo importante es la conexión con el público (cf. Fernández 2009) y por ello hay que proporcionarle literatura acomodada al entorno sociocultural en el que se desenvuelve, nacionalizando los textos objeto de traducción.

Éstas son las normas que publica el periódico L 'Anné Literaire sobre el proceder traductológico.

- Prohibir todo lo que fuese bajo y ordinario en el idioma y en los hechos.

- Prohibir la extravagancia en el idioma.

- Proscribir las escenas demasiado violentas o afectivas.

(Pajares 1996: 993)

Aunque las reglas francesas por excelencia provienen de Batteux (en sus Principes de Littérature):

I. Que no debe alterarse el orden de las cosas, ya sean hechos o razonamientos. [...]

II. Que debe conservarse también el orden de las ideas, o por lo menos de los miembros. [...]

III. Que deben observarse los períodos, por largos que sean, porque un periodo no es más que un pensamiento compuesto de otros varios pensamientos relacionados entre sí por vínculos intrínsecos [...]

IV. Que deben conservarse todas las conjunciones [...]

V. Que todos los adverbios debe[n] colocarse junto al verbo $[. .$.
VI. Que las frases simétricas se expresarán con su simetría o un equivalente [...]

VII. Que los pensamientos brillantes, para conservar el mismo grado de luz, deben tener más o menos la misma extensión en las palabras [...]

VIII. Que hay que conservar las figuras de pensamiento [...] En lo relativo a las figuras de dicción, como son las metáforas, repeticiones, caídas de nombres o de verbos, ordinariamente pueden sustituirse mediante equivalentes [...]

IX. Que los proverbios, que son máximas populares y que vienen a ser una sola palabra, deben expresarse mediante otros proverbios [...]

X. Que toda paráfrasis es viciosa. Ya no es traducir, es comentar [...]

XI. Finalmente, que hay que abandonar del todo la manera del texto que se traduce cuando el sentido lo exige para la claridad, o el sentimiento de la vivacidad, o la armonía para el agrado.

(Citado en Ruiz Casanova 2000: 334-335)

De ahí que no resultase extraño encontrarse con las siguientes declaraciones:

Pero, lejos de ceñirme a una traducción rigurosa y literal, me he tomado la libertad [en de] suprimir, aumentar o alterar no pocos lugares (aunque sin apartarme demasiado de la substancia y del método original) ya con el fin de corregir varias equivocaciones, ya con el de aclarar doctrinas que no parecerían acomodadas a la comprensión de los niños o ya para evitar ciertas repeticiones molestas y algunas digresiones que los distraerían del principal asunto" (Campe 1789: X-XI; citado en Lafarga 2004: 222).

Cuando traduzca, lo haré libremente, y jamás al pie de la letra; alteraré, mudaré, quitaré y añadiré lo que me pareciese a propósito para mejorar el original, y reformaré hasta el plan y la conducta de la fábula cuando juzgue que así conviene (Trigueros 1804: XXXII). 


\section{RETAZOS DISCURSIVOS DE LA HISTORIA DE LA TRADUCCIÓN}

Entreculturas 11 (2021) pp. 20-35

\section{LA PLUMA DE DRYDEN}

Es imprescindible traer a colación a Dryden (1631-1700): su pensamiento va a ejercer una influencia importantísima en la práctica de la traducción e interpretación de la centuria ilustrada (cf. Kelly 2005: 67-95). Como bien refleja Steiner en el prólogo de su obra English Translation Theory (1975), muchos académicos y estudiosos de la traducción lo catalogan como "the lawgiver to translation" o, en español, “el preceptista de la traducción”. Así Samuel Johnson llegó a sentenciar "it was reserved for Dryden to [...] give us just rules and examples of translation” (Steiner 1975: 68).

We are bound to our author's sense, though with the latitudes already mentioned; for I think it not so sacred, as that one iota must not be added or diminished, on pain of Anathema. But slaves we are and labor in another man's plantation; we dress the vineyard; but the wine is the owner's: if the soil be sometimes barren, then we are sure of being scourged: if it be fruitful, and our care succeeds, we are not thanked; for the proud reader will only say, the poor drudge has done his duty: But this is nothing to what follows; for, being obliged to make his sense intelligible, we are forced to untune our own verses, that we may give his meaning to the reader. $\mathrm{He}$, who invents, is master of his thoughts and words: he can turn and vary them as he pleases, till he renders them harmonious; but the wretched translator has no such privilege: for, being tied to the thoughts, he must make what music he can in the expression; and, for this reason, it cannot always be so sweet as that of original" (Dryden, en la traducción de la Eneida; citado en Lefevere 1992: 24).

La introducción a las Epístolas de Ovidio es, como apunta Steiner (1975: 68), el punto de partida de cualquier tipo de discusión posterior acerca de la traducción en el siglo XVIII. En ella puede leerse la visión tripartita que Dryden tiene sobre los métodos de traducción: metaphrase, paraphrase e imitation:

\section{METAPHRASE}

"or turning an author word by word, and line by line, from one language to another" (Steiner 1975:68).

En este caso estaríamos ante lo que conocemos como "traducción literal", que Steiner ejemplifica con las palabras de Horacio que hemos citado antes: "Nec verbum verbo curabis reddere, fidus Interpres...”

\section{PARAPHRASE}

[...] or translation with latitude, where the author is kept in view by the translator, so as never to be lost, but his words are not so but not altered [...] (Steiner 1975: 68).

Podríamos decir que este término hace alusión al tipo de traducción en el que el traductor no se centra en la traslación de palabras, pero sí de sentidos.

\section{IMITATION}

[...] where the translator (if now he has not lost that name) assumes the liberty, not only to vary from words and sense, but to forsake them both as he sees occasion; and taking some general hints from the original (Steiner 1975: 68).

Las imitaciones son prolíferas en el siglo XVIII, donde al no existir propiedad intelectual se presentan originales como copias; y donde la traducción manipulada es una de las tónicas de la época. Así podemos encontrarnos con traducciones que versionan el TO (texto origen), que lo abrevian, que lo amplían, que lo utilizan como si de un "collage" se tratara, que lo recrean, etc.

For Dryden, it is a bad translator (or painter) who so studies his style that throughout the work his hand may be seen but not the individuality of the original (Steiner 1975: 38). 


\section{Lía de Luxán Hernández \\ Entreculturas 11 (2021) pp. 20-35}

He aquí una lista de requerimientos que Dryden en los albores de su carrera como traductor consideró que debían reunirse en la persona del traductor, para que así pudiese ejercer su profesión en términos correctos. Según Johnson, el motivo fundamental que le llevó a establecerlos fue el hacer frente a la anarquía individual de preferencias y opiniones (Steiner 1975: 28). Parte de estos preceptos son doctrina común en los estudios de traducción contemporáneos y caracterizan el concepto de competencia traductora actual:

1. Be a poet.

2. Be master of both the language of the original and his own

In his work he should:

3. Understand the characteristics that individuate his author.

4. Conform his genius to that of the original.

5. Keep the sense "sacred and inviolable" and be literal where gracefulness can be maintained.

6. Make his author appear as "charming" as possible without violating his real character.

7. Be attentive to the verse qualities of both the original and the English poem.

8. Make the author speak the contemporary English he would have spoken.

There were strictures too:

9. Do not improve the original.

10. Do not follow it so closely that the spirit is lost.

No obstante, hay que subrayar que Dryden cree en reglas bajo ciertas circunstancias, bajo ciertas condiciones, pues las realidades no son constantes, sino heraclitianas, es decir, variables. Galván (2003: 11) también se muestra partidario de considerar que las condiciones desempeñan un papel no desdeñable, sino crucial, en la traducción de textos; nosotros sostenemos también esta postura, de ahí que defendamos la existencia de teorías particulares en la traducción (cf. De Luxán Hernández 2012, 2015, 2019), así como de la domextranjerización (cf. De Luxán Hernández, 2021 -artículo inédito en prensa-)
The translation is not only a version of the original text but a combination of that original text and the circumstances (social, political, economical, ideological and of course aesthetic) under which it was produced and published (Galván 2003: 11).

\section{LA TRADUCCIÓN DEL SIGLO XVIII ESPAÑOL}

La manía de la traducción ha llegado a su colmo. Nuestro país, en otro tiempo tan original, no es en el día otra cosa que una nación traducida (De Mesonero 1967: 277; citado en Pajares Infante 1996: 991).

En la traducción del siglo XVIII español influyeron los siguientes factores socio-económicos: la inexistencia del derecho de propiedad intelectual y los restantes derechos de autor; la censura política y religiosa (cf. Pajares 1994, 1996; García Garrosa 2005); el afrancesamiento y, por ello, también, las normas francesas del buen gusto (cf. Martinell 1989, Fernández Gómez y Nieto Fernández 1991; Pajares 1994, 1996, 2000; Lafarga 1996, 2004; Ruiz Casanova 2000; Fernández 2009; García Garrosa y Lafarga 2004, 2009); la necesidad económica (cf. Pajares 1994, 1996; Lafarga 2004); la incompetencia traductora (cf. Isla 1745; Memorial Literario 1793; Capmany 1798; García Garrosa y Lafarga 2009); los intereses editoriales (cf. García Hurtado 1999); el saberse país atrasado en los avances científicos; el repentino interés por las lenguas extranjeras en uso (cf. Lafarga 1996, 2004); las ideas universalistas de la ilustración; los intereses editoriales (cf. Pajares 1999; García Garrosa y Lafarga 2009): la traducción como producto y objeto de lucro; el interés por el receptor: no dejar que la rectitud moral, acorde con el conservadurismo católico, flaquee por la influencia de lo extranjero y las modernidades de otros países, y, entre otras cosas, guiar al nuevo lector en la lectura por medio de un nacionalismo en la traducción.

La expansión de las relaciones culturales, la influencia del movimiento de la Ilustración, la paulatina facilidad de acceso a las lenguas extranjeras, la cada vez más tenue he- 


\title{
RETAZOS DISCURSIVOS DE LA HISTORIA DE LA TRADUCCIÓN
}

\author{
Entreculturas 11 (2021) pp. 20-35
}

gemonía de las lenguas clásicas y, como antítesis, la aceptación de las lenguas vulgares como vehículos autorizados de conocimiento, etc. provocaron que en el siglo XVIII aumentase de manera considerable la necesidad de la práctica traductológica. Como consecuencia a ello, se experimentó un auge importantísimo en la demanda de traductores, lo que significó que hubiese muchos aventureros en el mercado de la comunicación bilingüe equivalente y que las críticas negativas hacia los trabajadores en este campo no se hiciesen de esperar.

Las traducciones que se efectúan durante el siglo de las luces parten, en su gran mayoría, de las versiones francesas. Ello explica el motivo por el que una de las preocupaciones de más relieve durante el siglo de las luces sea la lucha por la conservación de la lengua castellana, contaminada por la francesa debido tanto al gusto por lo francés y a la introducción de las modernidades provenientes de Francia, como a las traducciones de textos franceses y del francés (es decir de textos provenientes de otras "lengua-culturas", utilizando el francés como lengua puente).

A la hora de configurar el aura de la que se rodeó la traducción de esta época, se ha también de hacer mención a las rencillas y los celos personales y profesionales que hicieron mella en las críticas de las obras traducidas. Lafarga apunta el caso de Tomás de Iriarte, a quien le disgustó mucho que Juan José López de Sedano se basase en la traducción hecha por Vicente Espinel del Arte poética de Horacio, y, por ello, en la introducción de su versión se dedicó a criticar la labor que había sido llevada a cabo por Espinel (2004: 236-238).

Como ya se ha hecho hincapié, en esta centuria, no era extraño encontrarse con traducciones firmadas como originales y versiones mutiladas por la censura o la ideología. Fueron las penurias económicas y la no existencia de derechos de propiedad intelectual y de autor las causas motoras de que muchas traducciones se disfrazasen de originales, lo que dificulta el estudio de la historiografía de las obras traducidas en esta centuria. Aun así, se cuantifica la producción propia en torno a un 20\% (cf. Aguilar Piñal 19812001; Fernández y Nieto 1991; García Hurtado 1999; Buiguès 2002, García Garrosa y Lafarga 2004).
La labor traductora era concebida por el traductor dieciochesco como un servicio social, cuya utilidad se medía en función del género del TO (texto origen), del público y de la materia. La traducción desempeña una labor de educación, enriquecimiento nacional, progreso social, aunque ha de señalarse que las obras religiosas son las que más se traducen (cf. García Hurtado 1999). Los avances en el mundo científico y humanístico y las ideas que por aquel entonces inundaban Europa llegaron a España, a través de la función de intermediación del traductor. Se hizo uso de la traducción como una herramienta más y muy valiosa para la enseñanza de lenguas, y así las ediciones bilingües tuvieron aquí un papel importante pues eran un medio de que los aprendices de lenguas pudiesen comparar las estructuras gramaticales y aprendiesen vocabulario. A través de la traducción de obras del calibre de Historia natural de Buffon o de Arte poética de Boileau se intenta instruir a la juventud (cf. Clavijo 1791; Lafarga 2004; García Garrosa y Lafarga 2009).

Mas la traducción no era solamente un servicio para la sociedad: muchas personas vieron en ella una fuente de ingresos importante. Ello explica el motivo por el que escritores de la talla de Jovellanos, Cadalso o Moratín se dedicasen a la traducción; y justifica también que personas sin la competencia necesaria para desempeñar esta tarea se infiltrasen en ese mundo.

En los tiempos que corren, es desdichada la madre que no tiene un hijo traductor (José Francisco de Isla; citado en J.C. Santoyo 1987: 108).

La traducción efectuada por el sexo femenino fue presentada como un estímulo para que las mujeres se dedicaran a la tarea traductora. Su papel en este terreno fue notorio y se dedicaron a la traducción de todos los géneros (cf. LópezCordón 1996; García-Garrosa 1998; García-Garrosa y Lafarga 2009). García Hurtado, que ha cuantificado las obras traducidas al español de textos escritos originalmente en otra lengua (descartando los manuscritos) durante los años 1750 y 1808, encuentra veintiún casos en los que la mujer traduce, y, en la mayoría de ellos, del francés (1999: 41). 


\section{Lía de Luxán Hernández}

En lo que a las técnicas de traducción se refiere, se plantea la clásica disyuntiva entre fidelidad y libertad:

\begin{abstract}
[...] la primera y principal obligación entre las obligaciones de cualquier traductor [es] el ser fiel y exacto (Flórez Canseco 1781: V).

No me he valido de la libertad de algunos traductores que han juzgado satisfacer su oficio con pasar a su idioma los pensamientos del original, olvidándose enteramente de las gracias y adornos de la lengua traducida. Yo creo que el traductor debe expresarlo todo fielmente en la suya, o ya con las mismas expresiones o voces, si las dos lenguas tuviesen alguna afinidad, o ya con otras equivalentes, si en el todo o en parte les faltase correspondencia [...] Ni he servido tan vil y cobardemente a la letra del original que al modo que si fuese una escritura canónica haya hecho una especie de religión el no separarme un ápice de ella (García Asensio 1801: X, XI).
\end{abstract}

Aunque, en términos generales, a la traducción del siglo XVIII podrían atribuírsele los objetivos de "tutelada” " “manipulada”, debido a que el traductor no va a poder ejercer su oficio con total libertad: su labor va a quedar censurada por normas morales, estéticas y políticas. El trasvase de textos que atenten contra el poder político español no va a estar permitido, y se suprimirán todas las alusiones negativas al respecto; también ha de hacerse referencia al hecho de que todo aquello que vaya en contra de la fe cristiana no será objeto de traducción, y en lo que concierna a otras confesiones no habrá un proceder común: o bien se modificarán ciertos aspectos, o bien no se hará mención alguna.

A este respecto, García Hurtado (1999) señala que la traducción del setecientos española se enfrenta a dos tipos de obstáculos: uno ideológico-político, representado por la Corona y la Inquisición; y otro lingüístico, al que pertenecen los defensores del purismo de la lengua y que rechazan todo tipo de intrusismo en forma de neologismos, expresiones, estructuras, etc.

Mas, como advierte Pajares (1999: 345), la traducción española del siglo ilustrado es infiel al TO (texto origen) no solamente por motivos políticos o religiosos o reglas del buen gusto francesas de por sí, sino por las traducciones francesas en las que se basan: los cambios que se efectúan en las versiones españolas de las obras objeto de traducción no son en su mayoría genuinas de la pluma del traductor. Las traducciones se llevan a cabo a partir de un TM (texto meta) francés, lo que motiva a Pajares a plantearse si los TM españoles "son literal servilismo con respecto al TM1 [la traducción francesa], o concienciación y aceptación de un modo de traducir”. No obstante, se decanta por la primera opción y contempla que la concepción que tengan los traductores franceses de nacionalidad y de los intereses del nuevo receptor va a ser la que sus homónimos españoles adopten. Las diferencias radican, según él, en las peculiaridades de la propia censura española.

García Yebra califica la práctica traductora de esta centuria de "tradición" (1987: 27, citado en Pajares 1996: 1.000), lo que Pajares secunda empleando las siguientes palabras:

La tradición que nos legaron los traductores del XVIII y, en particular, la ampliamente difundida traducción tutelada, son exponentes del discurrir de una época, de que la historia se escribe de muchas maneras y de que difícilmente puede haber traición donde no hay libertad (Pajares, 1996: 1.000).

Pajares (1994 y 1996b) nos habla de "traducción tutelada" cuando describe el quehacer traductor de la época que nos ocupa, precisamente por la falta de libertad a la que se veía sometida la práctica de la traducción por tener que plegarse a las normas francesas del buen gusto y a la censura política y religiosa española, así como a la censura que el propio traductor imprimía a sus versiones por sus convicciones morales o ideológicas, y a la autocensura de sus convicciones a sabiendas de una posible censura posterior. Así podemos hablar de cuatro tipos de traducción tutelada: la censurada por el poder político; la censurada por el poder religioso; la censurada por las normas francesas del buen gusto; y la autocensurada, cuyas razones podrían recogerse en cualquiera de las tres precedentes. 


\title{
RETAZOS DISCURSIVOS DE LA HISTORIA DE LA TRADUCCIÓN
}

\author{
Entreculturas 11 (2021) pp. 20-35
}

Urzainqui (1991), basándose en la observación de los prólogos de un corpus de cien obras extraídas en su mayoría de la Biblioteca del Instituto Feijóo del siglo XVIII, en el que los traductores declaran sus intenciones, considera que las traducciones se efectuaban para restituir, seleccionar, abreviar, acumular, corregir, continuar, recrear, nacionalizar, generalizar, actualizar, traducir y parafrasear, entre otros motivos.

A juicio de Pajares (1996a), las teorías de la traducción de esta centuria podrían agruparse en dos grandes bloques: la vertiente clásica (Capmany, Covarrubias, Ranz Romanillos, Tomás de Iriarte...) y la renovadora (Cándido María Trigueros, Calderón de la Barca, García Malo...). El porqué de la elección de estos nombres encuentra su razón de ser en que los clásicos parten de las máximas asentadas por Aristóteles, Horacio y Cicerón; es decir, mientras que los renovadores -también calificados de imitadores por $\mathrm{Pa}$ jares Infante debido a la falta de originalidad de su doctrina, que imita a la francesa- se muestran más flexibles y amplían el concepto de equivalencia. No obstante, consideramos que ambas posturas son encuadrables dentro del concepto de mímesis.

Según Pajares(1996a: 169 -170), los principios comunes de la vertiente clásica, que giran en torno al eje fundamental de la consideración de la lengua como objeto -axioma también predicable de la teoría lingüística (siglo XX) - , podrían resumirse de la siguiente manera: énfasis en el dominio de ambas lenguas (LO -lengua origen- y LM -lengua meta-), concepto de equivalencia basado en la fidelidad al autor y al texto (se centra fundamentalmente en el sentido, el estilo y las figuras retóricas); interés en la práctica de la labor teórica de la traducción; necesidad de descontaminar la lengua española de los galicismos; familiaridad con el asunto que se traduce; respeto al orden de los conceptos y al tipo de oración; alabanza de la tarea del traductor, que es considerada de gran trascendencia; y asentamiento de las diferencias entre el lenguaje culto y el coloquial.

Las discrepancias fundamentales de este grupo de teóricos de la traducción que ha sido bautizado de "clásicos" por Pajares, vienen servidas de la mano del concepto de equivalencia: se debaten entre los conceptos que encie- rran los términos metaphrase (equivalencia formal) y $p a-$ raphrase (equivalencia dinámica). Capmany es totalmente partidario de este segundo planteamiento y asevera que la traducción literal (que sería la recogida bajo el paraguas de la metaphrase) debe condenarse por no ofrecer una buena versión; está a favor de la traducción total (asunto, estilo, imágenes y figuras retóricas), de la traducción fotográfica -aquella que se presenta como una copia del original, en la que tanto las virtudes como los defectos del TO (texto origen) son visibles - y realiza una crítica feroz de la traducción que se sale de estos cánones (1996a: 168-169).

En qualquier arte el original se ha de mostrar en la
copia, y en el de traducir ésta debe ser siempre fiel
al sentido, y si es posible a la letra del autor. [...] es
preciso descubrir la fisyonomía del autor. No por
esto pretendo que un traductor se sujete a trasladar
palabra por palabra, sino que conserve la calidad y la
fuerza de ellas (Capmany; citado en Ruiz Casanova
2000: 321).

Tomás de Iriarte, sobrino de Juan de Iriarte, se nutre de la doctrina neoclásica, aunque su postura se extiende más allá de estos horizontes: "Sentemos desde luego que no siempre conviene traducir; a veces es preciso explicar, que es un poquito más que traducir" (citado en Pajares Infante, 1996a: 168). Se puede colegir que aquí ya no se habla de traductor, sino que se hacer referencia a la función de un semiautor o semitraductor (así Covarrubias).

El denominador común de la corriente renovadora es la veneración al receptor, lo que la convierte en la antagónica de la clásica, donde el autor era el foco de atención. Así cualquier modificación se justifica con las siguientes palabras: "obra corregida y acomodada a nuestras costumbres por el traductor". El concepto de equivalencia da, por lo tanto, un nuevo rumbo; las palabras de Mariano José de Larra (1997: 483) son una muestra de ello:

[...] traducir en materias de teatro casi nunca es interpretar: es buscar el equivalente, no de las palabras, sino de las situaciones 


\section{Lía de Luxán Hernández \\ Entreculturas 11 (2021) pp. 20-35}

Lo pernicioso de esta postura es el empobrecimiento cultural, el individualismo...; aunque hay que alabar la preocupación por el receptor (aquí en desmedida), y es que para llegar a un equilibrio, para lograr la virtud aristotélica, los excesos son necesarios. De ahí que, por ejemplo, el nihilismo de Nietzsche fuese de vital importancia para llegar al raciovitalismo de Ortega y Gasset.

En el siglo XVIII, no se habían dado todavía cita la lingüística en sentido moderno, la pragmática, la sociolingüística, la psicolingüística, la semiótica, etc. Aún así, podríamos concluir diciendo que estas disquisiciones teóricas eran, son y serán siempre las mismas, con mayor o menor acierto, y con mayor o menor fundamento. En palabras de Pajares (1996: 74):

\section{[...] quizá, desde un punto de vista conceptual, no hemos avanzado tanto como imaginamos y conti- nuamos dando vueltas y más vueltas al mismo moli- no. Eso sí, ahora con nombres mucho más rimbom- bantes y engolfados en querer descubrir las reglas que nos digan cómo expresar los más recónditos sentimientos de un Mr. Wilson en un Sr. González.}

\section{LA TRADUCCIÓN DEL SIGLO XVIII INGLÉS}

El estudio de la traducción inglesa ilustrada no tiene porqué situarse entre 1700 y 1799, pues, como apunta Fernández (2009: 131), existen muchos historiadores que consideran el XVIII inglés como un siglo largo, que abarca desde la Revolución Gloriosa (1688) hasta la batalla de Waterloo (1815), la muerte de Jorge III (1820) o la reforma parlamentaria (1820). No obstante, aquí nos centraremos en el siglo XVIII propiamente dicho.

Muchas de las características que describen la traducción ilustrada española sirven para dibujar la traducción inglesa del setecientos. Durante esta centuria se produjeron muchas traducciones: se trataba de un negocio de pane lucrando (al igual que en España) y en el que se implicaban todo tipo de perfiles profesionales (cf. Hopkins y Rogers 2005; García Garrosa 2009). La producción inglesa propia era muy inferior a las obras que se importaban por medio de la labor traductora (cf. Gillespie 2005). La influencia francesa, como se ha señalado más arriba, desempeña un papel importante en la concepción de cómo llevar a cabo una traducción.

La estética francesa, el decoro, el buen gusto, la superioridad moral, etc. van a estar muy presentes durante el período augústeo de la traducción inglesa del siglo XVIII, lo que explica el proceder traductor de la época, que, en vez de mirar al TO y su autor, se centraba en el lector y su educación.

Fernández (2009), siguiendo el planteamiento de Steiner (1975) y basándose asimismo en las pesquisas de Draper (1921) y Abrams (1953), concibe que en la traducción ilustrada inglesa se advierten dos grandes corrientes: los traductores encuadrables en el período augústeo, en el que reina el concepto de mímesis; y los pertenecientes a la transición al romanticismo, en el que la originalidad es el lema representativo.

Los traductores de la corriente neoclásica (período augústeo) se nutren o bien del concepto de mímesis en su vertiente platónica (idealismo trascendental), según Fernández (2009: 150), o bien del concepto de mímesis en su vertiente aristotélica (idealismo empírico), como se deduce de las palabras de Steiner (1975: 39-40).

\footnotetext{
I have endeavour'd to express what I conceiv'd to be the Sense and Meaning of the Author, in as full and comprehensive Words as I was able, attending all along to the principal Scope and Design of his Discourse, rather than to the particular Words and Expressions (Thomas Cockman, 1732: xii; citado en T.R. Steiner, 1975:40).
}

Las palabras de Cockman sirven de justificación del modelo "idealismo empírico", pues el traductor se atiene a lo que subyace en el texto. Mas, si tenemos en cuenta que se traduce adaptando el TO (texto origen) a las buenas costumbres, recta moral y buen hacer, es decir, a lo que en realidad debería ser, al mundo que no está ensombreciendo la realidad, al verdadero mundo de las ideas, etc., le daremos la razón a Fernández y concluiremos que la bandera de esta corriente traductora es el idealismo platónico. 


\section{RETAZOS DISCURSIVOS DE LA HISTORIA DE LA TRADUCCIÓN}

“Decoro" es la palabra que, sin lugar a duda, define para Draper (1921) la centuria ilustrada, aunque, a nuestro parecer, y teniendo en consideración las palabras de Fernández (2009) y Steiner (1975), encaja más bien con esta corriente traductora, que, en definitiva, es la que caracteriza el siglo XVIII. Este enfoque teórico propugna la exaltación de lo nacional y la consideración de la superioridad moral, cultural e ideológica inglesa con respecto a la cultura clásica por el hecho de ser una civilización pagana; ello conllevó a que muchas de las traslaciones de textos fuesen lo que hoy en día conocemos como adaptaciones strictu sensu.

Por el contrario, los teóricos de la traducción pertenecientes a la corriente prerromántica no se guían por el concepto de "mímesis", sino por el de "originalidad": se trata de respetar la personalidad del autor del TO (texto origen), sus ideas, su creatividad, su genio, su imaginación (cf. Steiner 1975: 38-60 y Fernández 2009: 154-155), lo que acarreó que la traducción literaria ganase más protagonismo (cf. Draper 1921: 244-245 y Fernández 2009: 154-155).

The distinctive qualities of the original, even perhaps a characteristic mole or blemish, are not for the translator to alter. For him to do so would be analogous to a painter's ignoring or remarking the natural world (Steiner 1975: 38).

He that imitates the divine Iliad, does not imitate Homer; but he who takes the same method, which Homer took, for arriving at a capacity for accomplishing a work so great. Tread in his steps to the sole fountain of inmortality; drink where he drank, at the true Helicon, that is, at the breast of Nature. Imitate; but imitate not the composition, but the man. For may not this paradox pass into a maxim? viz.; "The less we copy the renowned ancients, we shall resemble them the more" (Edward Young, Confectures on Original Composition in a Letter to the Author of "Sir Charles Grandison”, 1759; citado en Steiner 1975: 49).
Tytler publicó en el año 1791 su Essay on the Principles of Translation, la obra más importante del siglo XVIII en el terreno de la traducción, que, como señala Steiner (1975) se trata del primer tratado en sí redactado en inglés sobre la materia (se ha hecho uso de la versión de 1813, por lo que a esa versión nos referimos en cada una de las citas de esta obra).

[Translation is] that, in which the merit of the original work is so completely transfused into another language, as to be as distinctly apprehend, and as strongly felt, by a native of the country to which that language belongs, as it is by those who speak the language of the original work (15).

De esta definición extrae las tres reglas básicas de traducción, pidiendo disculpas en el prólogo de su obra por la generalidad con la que trata esta materia, pues no pretende ser exhaustivo.

\section{1a) That the translation should give a complete trans- cript of the ideas of the original work (17-33).}

Para ello presupone que el traductor debe poseer conocimientos extralingüísticos (sobre la materia de la que versa el TO -texto origen-) y dominar tanto la lengua de partida como la de llegada, pues ésa es la única manera de poder interpretar de manera correcta el sentido de las palabras del autor.

Tytler matiza esta norma (35-61) al plantearse si el traductor tiene licencia para la adición y supresión de fragmentos, llegando a la conclusión general de que el traductor debe actuar con juicio y asumiendo el carácter del autor del TO: añadirá así fragmentos para reforzar el pensamiento del autor, nunca entrando en contradicción con él; y suprimirá aquello que sea redundante; eso sí, se entiende que dentro de ciertos límites, y no faltando nunca a la ética profesional (Tytler nos muestra ejemplos de traducción en los que estas decisiones son manipulaciones, y ello no debe aplaudirse). 


\section{Lía de Luxán Hernández}

\section{2a) That the style and manner of writing should be of the same character with that of the original (109-139).}

Esta segunda norma es calificada por el autor como de mayor dificultad en lo que a su observancia se refiere, pues las habilidades que se precisan para discernir e imitar el estilo y modo de escritura de un autor son de mayor complejidad que las necesarias para la comprensión del sentido de un texto. Fracasará, por ende, el traductor que no logre transmitir la pluma del autor del TO (texto origen), al menos de una manera aproximada, pues, por ejemplo, no es aceptable hacer uso de un estilo vulgar en un TM (texto meta) si el escritor del correspondiente TO es fiel a un lenguaje exquisito y pulcro con la gramática. Así Fraser escribe:

\begin{abstract}
If we are thus justly offended at hearing Virgil speak in the style of the Evening Post or the Daily Advertiser, what must we think of the translator, who makes the solemn and sententious Tacitus express himself in the low can 't of the street, or in the dialect of the waiters of a tavern? (119).
\end{abstract}

Tytler recurre al Antiguo Testamento, en concreto, al primer capítulo del Génesis, para ejemplificar lo que sería una buena traducción, en consonancia con esta segunda norma; nos señala que el estilo de las Sagradas Escrituras es simple, y que, en realidad, ello se debe, principalmente al lenguaje en sí: al hebreo. Así una traducción que fuese al inglés, imitadora este estilo, sería la siguiente:

In the beginning God created the Heaven and the Earth. 2. And the earth was without form, and void. 3. And darkness was upon the face of the deep. 4 . And the spirit of God moved upon the face of the waters. 5. And God said, let there be light. 6. And there was light. 7. And God saw the light, that it was good. 8. And God divided the light from the darkness. 9. And God called the light day. 10. And the darkness he called night. 11 . And the evening and the morning were the first day (111-112).
Pero la captación del estilo del autor del TO (texto origen) no es un objetivo alcanzable en todas las ocasiones; de ahí que Tytler extraiga, en lo que a la traducción al inglés se refiere, las siguientes limitaciones (177- 199):

- This imitation must always be regulated by the nature of the genius of the languages of the original and of the translation.

- The Latin and Greek languages admit of inversions which are inconsistent with the genius of the English.

- The English language is not incapable of an elliptical mode of expression; but it does not admit of it to the same degree as the Latin.

\section{3 ) That the Translation should have all the ease of the original composition (209-227).}

De esta regla se deduce que el TM (texto meta) debe cumplir la misma función que el TO (texto origen), causar el mismo efecto en el público receptor y, en definitiva, gozar de todas las características e imágenes del texto primigenio. Mas para conseguir que el TM sea como el TO no basta con captar el sentido de la obra original y lograr transmitirlo en la nueva producción, ni tampoco es suficiente con que se imite, al mismo tiempo, el estilo del autor. Ello se debe a que este último requisito propuesto por Tytler exige un nivel de perfección difícil de alcanzar por parte del traductor, porque la actividad traductora, que consiste en conseguir comunicaciones bilingües equivalentes (grosso modo este es el objetivo principal) nunca va a suplir la comunicación original entre el autor del TO y los lectores para los que fue pensado. Además, si tenemos en cuenta que los conocimientos compartidos entre el emisor y los distintos destinatarios son inestimables dado que cada individuo tiene su propia visión y conocimiento del mundo, llegaremos a la temible conclusión de que ningún texto produce el mismo efecto en cada persona, por lo que el traductor debe contentarse (estamos reflexionando sobre la traducción en términos generales y no solamente sobre el fenómenos de la traducción en la época ilustrada inglesa) con captar el 


\section{RETAZOS DISCURSIVOS DE LA HISTORIA DE LA TRADUCCIÓN}

sentir y la función general del TO para dar con un TM que sea fiel a esas generalidades.

\section{CONCLUSIONES}

Las palabras de Cicerón y Horacio estuvieron muy presentes en la literatura dieciochesca. La traducción del siglo XVIII es fruto de épocas anteriores y del entorno sociocultural en el que se desenvuelve; como hemos citado en la introducción a este artículo, D'Hulst (1994: 12-13) considera que el revisionismo histórico en el terreno de la traducción es importantísimo para la comprensión de cualquier período posterior; además, incita a la tolerancia, a la flexibilidad intelectual, a un entendimiento más unitario y global de la disciplina, y a que se puedan adoptar modelos y técnicas del pasado.

España y Gran Bretaña copiaron las teorías de traducción francesas, y el decoro y la estética que las caracterizaban influenciaron de manera muy notable en el concepto de traducción de estos dos países. Durante el siglo XVIII, España demandó muchas traducciones, y la traducción, en consecuencia, se convirtió en un negocio de pane lucrando en el que participaron traductores sin formación en ninguna de las lenguas, escritores profesionales que vieron en la traducción una salida laboral que les aportaba más beneficios que la producción de obras propias, editores que velaron únicamente por sus intereses económicos y no por la calidad en la traducción, entre otros.

La traducción dieciochesca inglesa, al igual que la española de la misma centuria, se vio muy influenciada por la estética francesa. La palabra "decoro" resume parte de la filosofía traductora de buena parte del siglo XVIII inglés y la censura que se imprimía en las traducciones.

Tytler escribió en 1791 su Essay on the Principles of Translation, obra de referencia obligada a la hora de estudiar la teoría de la traducción inglesa de esta centuria. En ella destaca tres normas de traducción: 1 a "That the translation should give a complete transcript of the ideas of the original work"; $2^{\mathrm{a}}$ "That the style and manner of writing should be of the same character with that of the original";
3 "That the Translation should have all the ease of the original composition".

\section{REFERENCIAS BIBLIOGRÁFICAS}

Abrams, M.H. (1953) [1971]: The Mirror and the Lamp. Romantic Theory and the Critical Tradition. Oxford, Oxford University Press.

Aradra Sánchez, R. Ma. (1999): "La traducción en la teoría retórico-literaria española (1750-1830)”. En Lafarga, F. (ed.). La traducción en España (1750-1830). Lengua, literatura, cultura. Lleida: Universitat de Lleida. Pp. 167-176

Aragón Fernández, Ma. A. (1991): "Una teoría de la traducción en el siglo XVIII: Covarrubias”. En Donaire, Maㅡ L., Lafarga, F. (eds.). Traducción y adaptación cultural: EspañaFrancia. Oviedo, Universidad de Oviedo, pp.531-539.

Ballard, M. (1992) : De Cicéron à Benjamin: Traducteurs, Traductions, Réflexions. Lille, Presses Universitaires de Lille.

Crespo Hidalgo, J. (1996): Reseña del libro de García Yebra, CF. Traducción: historia y teoría. Trans. № 1, pp. 186-192.

De Capmany, A. y S. De Montpalau (1776): Arte de traducir el idioma Francés al Castellano [Edición comentada por Fernández Díaz, Ma d. C.] (1987), Universidad de Santiago de Compostela, Servicio de Publicaciones e Intercambio Científico.

De Iriarte, T. (1778): Donde las dan las toman: diálogo joco-serio sobre la traducción del Arte Poética de Horacio que dio a luz D. Tomás de Yriarte y sobre la impugnación que de aquella obra ha publicado D. Juan Joseph López de Sedano al fin del tomo IX del Parnaso Español. Madrid: Imprenta de la Gaceta de Madrid. Memoria digital de Canarias. http:// bibmdc.ulpgc.es/cdm4/document.php?CISOROOT=/MD C\&CISOPTR $=75540 \&$ CISOSHOW $=75298$

De Isla, J.F. (1963): Fray Gerundio de Campazas. Madrid: Espasa-Calpe, S.A. Vol. III.

De Luxán Hernández, L. (2012): "Cómo enfrentarse a la traducción histórica: Estudio de la documentación que se genera entre España y Gran Bretaña con motivo del ‘Asiento de Negros'” En López-Folgado, CF. y M. RivasCarmona, (eds). Essays on Translation. Multilingual Issues. Hamburg: Verlag Dr Kovač; pp. 213-230. 


\section{Lía de Luxán Hernández}

Entreculturas 11 (2021) pp. 20-35

_ (2015): "La traducción en la historia y la historia en la traducción”. En Marcelo Wirnitzer, G. (coordinadora). Traducir la historia desde diferentes prismas. Universidad de Las Palmas de Gran Canaria: Servicio de Publicaciones; pp.339-362

(2019): La traducción histórica y el asiento de esclavos británico. Ed. Comares (colección interlingua)

_ (2021) «El viajero como traductor de conceptos: estudio de los hispanismos e indigenismos en "Der Wochenmarkt in Cartago" (1853)». Alpha. Revista de artes, letras y filosofía 52. (Artículo inédito en prensa).

Delisle, J. (2001) : «L'evaluation des traductions par l'historien », en Meta Translators's Journal, CF. 46, no 2, pp 209-216

_ (2003): "La historia de la traducción: su importancia para la traductología y su enseñanza mediante un programa didáctico multimedia y bilingüe" En Íkala, revista de lenguaje y cultura. Volumen 8, n 14.

Delisle, J. y J. Woodsworth (1995): Translators through History. Amsterdam \& Philadelphia, John Benjamins.

D’Hulst, L. (1 994): Enseigner la traductologie: pour qui et a quelles fins? Meta 39,1, pp. 8-14.

Draper, J. W. (1921): “The Theory of Translation in the Eighteenth Century”. En Neophilologus, 6.

Fernández Gómez, J. y N. Nieto Fernández (1991): “Tendencias de la traducción de obras francesas en el siglo XVIII”. En Donaire, Maㅡ. L., Lafarga, F. (eds.), Traducción y adaptación cultural: España-Francia. Oviedo, Universidad de Oviedo, pp. 579-591

Fernández, F. (2009): "La traducción en Gran Bretaña durante el siglo XVIII”. En Sabio Pinilla, J. A., La traducción en la época ilustrada. (Panorámicas de la traducción en el siglo XVIII). Granada, Comares.

Galván, F. (2003): “Translating the English Classics”. En The European English Messenger. Vol. 13o, pp. 11-16.

García Asensio, M. (1801): "Palabras del traductor al que leyere”. En Saverio BettinellI, F. Jerjes. Valencia, José de Orga, pp. I-XVI.

García Garrosa, Ma. J. (1996): "Trigueros traductor de Mercier: Sobre el origen de un relato de Mis pasatiempos". En Álvarez Barrientos, J. y Checa, J. (eds.). 1996. El siglo que llaman ilustrado. Homenaje a Francisco Aguilar Piñal. Madrid: CSIC.
(1998): “Mujeres novelistas españolas del siglo XVIII”. En Lara García, F. (ed.), Actas del I congreso internacional sobre novela del siglo XVIII. Almería, Universidad de Almería, pp. 165-176.

_ (2005): “' Copiando gálicas frases con españolas palabras': El filtro corrector de la censura en traducciones de obras francesas en el siglo XVIII español”. En Desprès, C. et al. (eds.). Homenaje al profesor D. Francisco Javier Hernández. Valladolid: Departamento de Filología Francesa y Alemana de la Universidad de Valladolid-APFUE, pp. 285-298. (2006): "El debate sobre las traducciones en España en el siglo XVIII: un espacio de opinión pública". En Cantos, $\mathrm{M}$ (ed.). Redes y espacios de opinión pública. De la Ilustración al Romanticismo. Cádiz, Europa y América ante la modernidad. 1750-1850. Cádiz: Universidad de Cádiz, pp. 541-533.

García Garrosa, Mํ. J. y F. Lafarga (ed.). (2004): El discurso sobre la traducción en la España del siglo XVIII. Estudio y antología. Kassel, Reichenberger.

_ (2009): "La historia de la traducción en España en el siglo XVIII". En Sabio Pinilla, J. A. La traducción en la época ilustrada (Panorámicas de la traducción en el siglo XVIII). Granada, Comares.

García Hurtado, M.R. (1999): "La traducción en España1750-1808: cuantificación y lenguas en contacto”. En Lafarga, F. (ed.), La traducción en España (1750-1830). Lengua, literatura, cultura. Lleida, Universitat de Lleida, pp. 35-43.

García Yebra, CF. (1979-1980): “¿Cicerón y Horacio preceptistas de la traducción?” En Cuadernos de Filología Clásica, XVI, pp. 139-154.

_ (1994): Traducción: historia y teoría. Madrid: Biblioteca Románica Hispánica. Editorial Gredos.

(1997): Teoría y práctica de la traducción. España: Gredos.

Horacio Flaco, Q. [65 A.C.-08 A.C.] (publicación de 2008) Ars poetica - traducida en verso castellano / [Tomás de Iriarte] - Alicante: Biblioteca Virtual Miguel de Cervantes; Madrid: Biblioteca Nacional

Kelly, L. G. (1979): The True Interpreter: A History of Translation Theory and Practice in the West. Oxford, Blackwell.

_ (2005): "The Eighteenth Century to Tytler". En The Oxford History of Literary Translation in English. Volume 3. 1600- 


\section{RETAZOS DISCURSIVOS DE LA HISTORIA DE LA TRADUCCIÓN}

Entreculturas 11 (2021) pp. 20-35

1790. Oxford y Nueva York: Oxford University Press, pp. 121-146.

Lafarga, F. (ed.) (1996): El discurso sobre la traducción en la historia. Antología bilingüe. Barcelona, EUB.

(1999): "Hacia una historia de la traducción en España (1750-1830). En Lafarga, F. (ed.). La traducción en España (1750-1830). Lengua, literatura, cultura. Lleida: Universitat de Lleida, pp. 11-29.

_ (1999): La traducción en España (1750-1830). Lengua, literatura, cultura. Lleida: Universitat de Lleida, pp. 35-43.

(2004): “El siglo XVIII, de la Ilustración al Romanticismo”. En Lafarga, F. y L. Pegenaute (eds.), Historia de la traducción en España. Salamanca, Ambos Mundos, pp. 209-319.

Lépinette, B. (1997): "La historia de la traducción. Metodología. Apuntes bibliográficos”. En LynX Documentos de Trabajo. Vol. 14

Londsale, R. (1993): Dryden to Johnson. London, Penguin.

López-Cordón, Ma․a․ (1996): “Traducciones y traductoras en la España de finales del siglo XVIII”. En Segura, C. y Nielfa, G. (eds.). Entre la marginación y el desarrollo: $M u$ jeres y hombres en la historia. Homenaje a María Carmen García-Nieto. Madrid: Ediciones del Orto, pp. 89-112.

Martinell, E. (1984): "Posturas adoptadas ante los galicismos en el siglo XVIII", Revista de filología. № 3, pp. 101-128.

Rener, F. M. (1989). Interpretation: Language and Translation from Cicero to Tytler. Amsterdam: Rodopi.

Ruiz Casanova, J.F. (2000): Aproximación a una historia de la traducción en España. Madrid, Cátedra.

Sabio Pinilla, J. A. (ed.) (2009): La traducción en la época ilustrada (Panorámicas de la traducción en el siglo XVIII). Granada, Comares.

Salas Salgado, F. (1999): “Observaciones sobre la traducción de Tomás de Iriarte de la Poética de Horacio”. En Lafarga, F. (ed.). La traducción en España (1750-1830). Lengua, literatura, cultura. Lleida: Universitat de Lleida, pp. 253-262

Santoyo, J.C. (1987): Teoría y crítica de la traducción: antología. Universitat Autònoma de Barcelona, Servei de Publicacions.

_ (1991): “Los estudios de traducción en España: estado de la cuestión y balance provisional” En Lépinette, B. et. al. (eds.), Actas del primer coloquio internacional de Traductología. Valencia, Universidad de Valencia, pp. 47-53

_ (2008): Historia de la traducción: viejos y nuevos apuntes. Universidad de León, Secretariado de publicaciones.

Steiner, T. R. (1975): English Translation Theory: 1650-1800. Approaches to Translation Studies 2. Amsterdam, Van Gorcum.

Trigueros Cándido, Maㅗ. (1804): “Prólogo, desengaño o engañifa”. Mis pasatiempos. Almacén de fruslerías agradables. Madrid, Viuda de López. I. V-XXIX.

Tytler, A.F. (1791, edición de 1813) Essay on the Principles of Translation. Amsterdam: John Benjamins

Urzainqui, I. (1991): "Hacia una tipología de la traducción en el siglo XVIII: los horizontes del traductor”. En Donaire, $\mathrm{M}$ a L y F. Lafarga. Traducción y adaptación cultural: España-Francia. Oviedo, Universidad de Oviedo, pp. 623-638.

Van Hoof, H. (1991) : Histoire de la traduction en Occident. Paris /Louvain-la-Neuve: Éditions Ducolot.

Vega Cernuda, M.A. (1996): “Hacia una recalificación del perfil del traductor”, Hieronymus Complutensis 3, pp. 42-50. (1996-1997): “Apuntes socioculturales de Historia de la traducción: Del Renacimiento a nuestros días”. El Escorial: La traducción en perspectiva. San Jerónimo: Revista del Instituto Universitario de Lenguas Modernas y Traductores. Universidad Complutense de Madrid. Disponible en el Centro virtual Cervantes. 4-5, pp. 71-85. 